\title{
VICENTE MUÑOZ DELGADO Y ÁNGEL AMOR RUIBAL
}

\author{
César Raña Dafonte \\ Universidad de Santiago
}

\section{RESUMEN}

Mi objetivo en este trabajo es presentar a Vicente Muñoz Delgado como estudioso y difusor de la filosofía de Ángel Amor Ruibal. Para ello me centro en los cinco estudios más interesantes del profesor Muñoz que versan sobre el filósofo compostelano.

Palabras clave: Muñoz Delgado, Amor Ruibal

\begin{abstract}
Vicente Muñoz Delgado and Ángel Amor Ruibal. With this work I pretend to introduce the readers to Vicente Muñoz Delgado like a studious and spreader of Angel Amor Ruibal's philosophy. To achieve this objective I'm going to take into account the most interesting five Writings by the professor Muñoz which deal with the exceptional philosopher from Santiago de Compostela.
\end{abstract}

Key words: Muñoz Delgado, Amor Ruibal

Vicente Muñoz Delgado y Ángel Amor Ruibal son dos filósofos nacidos en Galicia y su nombre forma parte, sin la menor duda, del grupo de filósofos españoles del presente siglo con enorme proyección. No es mi pretensión hacer una exposición del pensamiento y actividad filosófica de ambos autores. Mi objetivo es más modesto: presentar a Vicente Muñoz como estudioso y difusor de la filosofía de Ángel Amor Ruibal. Procuraré poner de manifiesto cómo es de los que han estudiado con más esmero y profundidad el pensamiento del filósofo compostelano. Sus trabajos publicados lo testifican abundantemente. Pero, antes de entrar en pormenores, diré algo sobre Ángel Amor Ruibal (1869-1930) y las circunstancias que rodean su actividad filosófica, que es la faceta en que vamos a centrarnos únicamente.

Las coordenadas espacio-temporales de su vida son muy sencillas: nació en una bonita aldea de la provincia de Pontevedra, vivió y trabajó en Santiago de Compostela en las primeras décadas de este siglo. Su tarjeta de visita bien podría ser: «Ángel Amor Ruibal, profesor del seminario y canónigo de la catedral de Santiago». Ni la tarjeta resulta especialmente significativa ni en su vida hay rasgos pintorescos. Además del sacerdocio, su profesión fue la de un profesor responsable y un investigador incansable. El resultado fueron amplias obras escritas. Desde el retiro de su aldea natal o desde su recóndita habitación en la casa de Santiago supo abrirse a la cultura y al pensamiento 
universal. Una persona casi nada viajera y con unos conocimientos tan amplios y diversos manifiesta una espléndida mirada intelectual.

El horizonte intelectual. Dado el lugar de sus estudios, Seminario de Santiago y Universidad Gregoriana de Roma, es razonable que conociese profusamente la doctrina vigente en la ortodoxia católica del momento: la neoescolástica (sobre todo, el neotomismo), de la que a partir de mediados del siglo XIX se restauró con fuerza su estudio. Finalizados los cursos académicos es cuando comienza su verdadera carrera intelectual, en que amplía conocimientos y horizonte. En la Universidad Civil de Santiago disponía de interesantes bibliotecas. Además, procuró él mismo hacer la suya propia, selecta y variada, sobre todo en los saberes relacionados con la neoescolástica. Estuvo muy al margen de círculos sociales. Podemos afirmar que, cuando se consagra a los estudios, estará muy ajeno de la vida cotidiana del momento. Así, en su pensamiento se aprecia un punto de vista intencionadamene intemporal.

En cuanto al lugar que ocupa la filosofía en la actividad intelectual de Amor Ruibal, hemos de decir que, aunque nunca ejerció como profesor de Filosofía, fue un filósofo de vocación. La filosofía fue su gran pasión. A pesar de sus otras facetas bien conocidas (teólogo, canonista, filólogo...), la parcela filosófica era la más entrañable y querida; por ello, todos sus escritos destilan filosofía.

Rasgos del filosofar ruibaliano. Como dejamos consignado, el lugar de donde parte es la neoescolástica. Pero llega un momento en que se da una ruptura muy honda con tal filosofía. No obstante, pretende ser educado y agradecido. Para llegar a esta situación, realizará previamente un análisis histórico-crítico y crítico-doctrinal de todo lo que implica la neoescolástica. Amor Ruibal, después de extensos análisis, rompe con esta tradición. Es lo primero que se aprecia en la amplia obra de nuestro autor. Cualquier mínimo conocedor de la historia de la escolástica comprende la ardua tarea que tal crítica precisa. Por ello, no es extraño que en la parte positiva y original del autor haya una temática, un método, incluso una terminología, que tienen resonancias escolásticas (era su patria de origen). Esto también explica que la filosofía contemporánea, naciente en su época (fenomenología, neopositivismo, existencialismo...), así como los autores extraescolásticos, en general, sean brevemente aludidos. En tiempos de Amor Ruibal ya no era abarcable toda la larga historia de la filosofía occidental en los análisis minuciosos que el autor realiza. Asimismo, esto explica por qué la parte positiva no ha sido publicada en vida. El propio Amor Ruibal nos aclara su actitud programática en filosofía con un texto bien conocido: «sin desdoro de los antiguos y de su labor grande cuanto entonces cabía, no sólo no se debe volver más al sincretismo incoherente y artificioso de ideas filosóficas encontradas, que hemos repetidamente observado, con la no menos artificiosa imprescindible alternativa de Platón y Aristóteles, sino que se hace necesaria una transformación honda en la teoría del ser y del conocer» (Los Problemas fundamentales de la Filosofía y del Dogma, vol. VI, pp. 636-637). Esto le llevará a la elaboración de un sistema propio, original.

\section{VICENTE MUÑOZ, ESTUDIOSO DE AMOR RUIBAL}

Una regla elemental de hermenéutica es que, para captar el pensamiento de un autor en su auténtico sentido y profundidad, se precisa un esfuerzo para situarse en el horizonte en que se mueve y desde el que ve la realidad el autor estudiado. Estimo que tal norma se cumple de modo 
paradigmático en el profesor Vicente Muñoz. También él conoció en su etapa de estudiante de Filosofía y Teología el pensamiento neoescolástico en profundidad. Manejó todos los escritos ruibalianos, publicados e inéditos. Realizó frecuentes y prolongadas estancias en los mismos lugares en que Amor Ruibal desarrolló su actividad. Todas estas circunstancias nos ponen de manifiesto cómo se trata de una persona perfectamente equipada intelectualmente para poder captar el auténtico pensamiento de Amor Ruibal. Si, por otra parte, tenemos en cuenta el rigor y la tenacidad en el estudio que el profesor Vicente Muñoz siempre ostentó, así como su facilidad para escribir, nos percatamos de que no sea casualidad el que se trate de uno de los máximos estudiosos y difusores de la filosofía del pensador gallego.

Centrado ya en los pormenores de esta faceta de Vicente Muñoz, voy a realizar una breve presentación de los principales trabajos al respecto. Aportaré en lo posible pasajes del propio autor, pues, no en vano la claridad y la precisión conceptual son las notas más salientes de todos sus escritos sobre Amor Ruibal. En la metodología a seguir, trataré de armonizar el orden cronológico de los escritos del profesor Muñoz y el contenido sistemático en relación con el autor estudiado. ${ }^{1}$ Concretando ya los trabajos que consideramos, son cinco estudios publicados entre los años 1968 y 1973. Como se aprecia fácilmente, giran en torno a una fecha clave en las investigaciones sobre Amor Ruibal, el año 1969, en que se conmemoró el primer centenario de su nacimiento, que sirvió de ocasión propicia para una promoción, inaudita en años anteriores, de la figura y pensamiento del hasta entonces muy preterido filósofo compostelano. A ello colabora Vicente Muñoz de manera generosa, espléndida.

\section{Introducción filosófica al primer centenario del nacimiento de Ángel Amor Ruibal, Estudios (PP. Mercedarios, Madrid), XXIV (1968), pp. 366-399}

Se trata de un precioso trabajo, que continúa siendo, a mi juicio, la mejor presentación de carácter introductorio de la actividad filosófica de Ángel Amor Ruibal. A los no iniciados en la materia les sirve de guía y orientación segura y clarificadora. Pone de manifiesto un conocimiento profundo y minucioso de todos los escritos ruibalianos, a veces densos y difíciles.

El trabajo consta de dos grandes apartados. El primero se centra en la presentación de la personalidad y talante de Amor Ruibal, así como de su tarea histórico-crítica en relación con la filosofía pretérita y de su tiempo. Sirva como representativo de esta primera parte el siguiente pasaje:

De esta primera parte y de lo anteriormente dicho podemos sacar las siguientes conclusiones. La dimensión filosófico-teológica de la obra del filósofo compostelano ha de medirse desde estas perspectivas:

1.) Sủ máxima preocupación es buscar un sistema filosófico, homogéneo y coherente, que con esas mismas cualidades permita una elaboración de la dogmática cristiana sin deformación del dato revelado y sin faltar a la lógica interna de los principios racionales establecidos.

1 Las citas de obras ruibalianas que aparecen en los distintos trabajos del profesor Muñoz se refieren a Los problemas fundamentales de la filosofía y del dogma, $10 \mathrm{vol}$. (PFFD), indicando entre paréntesis en números árabes el volumen correspondiente y a continuación la página (p.) o número (n.) interior de los mismos. Los cuatro manuscritos inéditos, los cita CMI, señalando a continuación la página. Si sólo aparece un número romano seguido de otros arábigos, se refieren al volumen y página de PFFD. 
$\left.2^{\circ}{ }^{\circ}\right)$ Ninguno de los sistemas escolásticos reúne esas cualidades de ser coherente y homogéneo; se trata de sincretismos, construidos con retazos de platonismo, neoplatonismo, estoicismo y aristotelismo con los que no fue ni es posible realizar ni el ideal filosófico ni el teológico. Cualquiera de los sistemas clásicos, digamos tomismo, escotismo, suarismo, o peca contra la lógica interna o lleva a absurdos filosóficos y teológicos.

$3^{\circ}$ ) Desde el primer volumen analiza A. Ruibal no solamente la filosofía escolástica, sino también las principales teorías modernas desde el positivismo hasta el idealismo transcendental, haciendo incursiones en las teorías y sistemas científicos más modernos. En ninguna de las corrientes estudiadas encuentra A. Ruibal las condiciones necesarias para la construcción del ideal filosófico en sí mismo y en su proyección teológica. Sería minimizarlo pensar que empieza su nueva construcción solamente a la luz de la filosofía escolástica. Es a la luz de toda la historia de lá filosofía. Toda ella está muy presente en su obra desde el principio hasta el final y al exponer su doctrina del conocer es tan moderno que se considera obligado a defenderse de posibles acusaciones de kantismo (8, págs. 539-549).

4. $\left.{ }^{\circ}\right)$ Por lo tanto, para realizar el ideal filosófico-teológico se impone una revisión honda de la filosofía, empezando por el problema del conocimiento. «La teoría cognoscitiva constituye el eje central de toda elaboración lógica y ontológica humana y, por ende, la base del sistema científico de la teología, que sobre conceptos humanos se apoya y es elaborado» (6, pág. 637). El problema del conocer es también, como se sabe, el centro sobre el que gira gran parte de la filosofía moderna.

5..$^{\circ}$ En una hoja de propaganda de Los problemas fundamentales, que servía de anuncio y suscripción de la misma obra, se describe así su contenido: «la crítica y detenido examen de este sistema [escolástico] de filosofía y de las soluciones que ofrece [...]; y las teorías, soluciones y opiniones del autor en cada uno de tales problemas [...] y que constituyen todo un sistema científico propio, original, vigoroso, y sano. Las teorías modernas y sus relaciones con la dogmática desde el kantismo y neokantismo en sus varias formas [...] hasta las últimas manifestaciones del pragmatismo y demás variantes filosóficas o filosófico-religiosas, halláranse en esta obra magistralmente expuestas, estudiadas e impugnadas». Este anuncio, que se acompañaba para la venta de la obra, refleja, sin duda alguna, la mente de A. Ruibal, si no estaba redactado por él mismo. Resume los tres aspectos que es necesario tener en cuenta para valorarlo debidamente, a saber, la crítica de los sistemas escolásticos en sí y en su proyección teológica, la crítica de la filosofía moderna en los mismos aspectos y la construcción de un sistema original distinto de todos ellos. He ahí condensada la empresa de este inmenso gallego (Vicente Muñoz Delgado, «Introducción filosófica», pp. 384-386).

La segunda parte del trabajo se centra en el análisis de las líneas fundamentales del sistema novedoso y original del filósofo estudiado:

Intento señalar solamente el horizonte peculiar donde hemos de colocarnos para penetrar la ideología original de este genial filósofo compostelano. La idea clave de toda su construcción la constituye la relación mutua, que, por esa razón, ha sido bautizada [...] como correlativismo o correlacionismo (ibídem. p. 386).

La exposición sintética del pensamiento ruibaliano que realiza a continuación aúna brevedad, claridad y profundidad. Como colofón de lo dicho, sirvan las siguientes advertencias que V. Muñoz considera esenciales para entender el pensamiento peculiar de Amor Ruibal:

Este correlativismo del ser y del conocer va metido en toda la elaboración científica o filosófica de A.R. Es fundamentalísimo darse cuenta de cómo concibe la potencia intelectiva 
formando un todo con el objeto: del engranaje de los dos van a salir todas nuestras construcciones intelectuales y eso es lo que va a dar profundo sentido de novedad al ruibalismo. Los objetos que conocemos no están enfrente, separados; los hacemos nosotros en parte, el hombre no es un espectador; el hombre parcialmente crea el objeto en virtud del engranaje y de la síntesis primera. Situándome en esa perspectiva correlativa del ser y del conocer me permito cuatro observaciones, para leer a A.R. con fruto:

$\left.1^{\circ}{ }^{\circ}\right)$ Como estas ideas están en el t. 8 y en él desarrolla el problema del conocimiento, «eje central de toda elaboración» (6, página 636), es por ahí por donde ha de empezarse el estudio de la obra del maestro compostelano. Debe seguirse su estudio por el tomo 9, 10 de $P F F D$ y los Cuatro manuscritos inéditos. Después de la meditación de esos tomos, puede empezarse la lectura reposada desde el primer volumen, que todo cobra nueva luz y grandeza. La exposición y publicación de Problemas fundamentales se ha hecho de manera poco ordenada, pero en el fondo hay una profunda unidad y una síntesis maravillosa.

El que empieza a leer por los primeros volúmenes se expone a no entender nada de las ideas propiamente tales del maestro.

$2 .^{\circ} \mathrm{A}$. Ruibal utiliza una terminología casi escolástica y un lenguaje duro y áspero; pero eso le da mayor precisión. El único peligro es dar a esos términos el sentido acostumbrado escolástico. Conocer, ente, esencia, categoría, universal, verdad, etc., tienen en A. R. un sentido diferente y es necesario un trabajo duro para llegar a dominarlo y no dejarse llevar por otras ideas ya asimiladas y expresadas por el mismo lenguaje.

$3{ }^{\circ}$ Es necesario para leer con fruto a A. R. saber liberarse del escuelismo, que tanto daño ha hecho al pensamiento filosófico sano, que por su misma naturaleza es independiente. No digo nada cuando de por medio hay un juramento para defender una determinada interpretación, muy problemática, de Santo Tomás. La verdadera disposición para filosofar la da este texto del mismo Angélico, totalmente contraria al espíritu del pernicioso juramento dominicano: «studium philosophiae non est ad hoc quod sciatur quid homines senserint, sed qualiter se habeat veritas» (De coelo, I, 2). Esta disposición de ánimo permitirá también contrastar críticamente la obra de A. R., evitando aquí otro nuevo escolasticismo.

$4^{\circ}$ ) Especialmente para juzgar un sistema relacional será muy necesario saber prescindir del absolutismo de las esencias y accidentes aristotélicos y de los aspectos sistemáticos de la escolástica. Eso es precisamente lo que está en tela de juicio. A.R. ha escrito: «una teoría muy lógica en sus conclusiones puede ser muy falsa en sus principios» (9, págs. 119-20). De los sistemas escolásticos critica A.R. sus principios, su génesis, sus elementos, la lógica interna de los mismos y su proyección teológica. La renovación que trata de hacer comprende tanto los principios de un nuevo sistema como sus consecuencias lógicas en el orden teológico y en el filosófico. La crítica ha de afectar a todos esos supuestos.

Con los principios tomistas siempre resulta falso el escotismo, y viceversa. Con la filosofía medieval proyectada sobre cualquier filósofo moderno encontraremos siempre en éste un sistema falso. Pero precisamente se trata de la construcción de un nuevo sistema y, por lo tanto, se han de examinar imparcialmente sus principios de manera independiente y no desde otro sistema. Lo contrario es negar el diálogo (ibidem. pp. 396-397).

\section{«Gnoseología y Ontología de Ángel Amor Ruibal»,Salmanticensis, vol. 15 (1968), pp. 597-640}

En este segundo escrito V. Muñoz desarrolla con cierta detención lo que esquemáticamente nos presentó en el anterior.

«En esta presentación voy a limitarme al estudio de su aspecto constructivo en filosofía, es decir, a señalar las líneas fundamentales de su pensamiento en dos puntos claves, que son la 
teoría del conocimiento y la ontología (Vicente Muñoz Delgado, «Guoseología y Ontología», p. 597).

Sin la menor duda, de la lectura de esta presentación se desprende una visión sumamente certera y clarificadora de la profunda teoría ontognoseológica de A. Ruibal.

La primera parte del trabajo versa sobre la teoría del conocimiento. Veamos la clarificadora conclusión:

«He señalado los aspectos fundamentales de la teoría del conocer de Amor Ruibal. En breves líneas podemos condensar algunas de sus características:

$\left.1^{\circ}{ }^{\circ}\right)$ No existe problema alguno para establecer un puente entre el sujeto y el objeto. La naturaleza nos lo ofrece ya en íntima unión, intrínsecamente correlacionados en la síntesis inicial. La misión del filósofo y el verdadero problema está en analizar los elementos de ese todo, que iremos conociendo mediante la reflexión sobre los hechos directos de la conciencia.

2. ${ }^{\circ}$ ) El hombre como sujeto cognoscente ha de considerarse incorporado en el engranaje universal de la naturaleza de la que forma parte, tanto en el orden entitativo como en el operativo. El hombre es actor destacado en el dinamismo universal. Sujeto y objeto se hallan unidos y preordenados. Materia y espíritu muestran su unidad en el hecho de la conciencia y de la sensación tanto en el ser como en el obrar. No son necesarios ni el entendimiento agente ni las especies, tanto sensibles como inteligibles, ya que espíritu y materia pueden tener una inmediata interacción en todos los niveles de entidad. El obrar inmediato del espíritu en la materia y de la materia en el espíritu se sigue de su íntima unión en el ser, sin intermediarios artificiales.

$3^{\circ}$ ) Nuestras percepciones son esencialmente correlativas a la presente organización de los sentidos del hombre, que podrían haber sido de otra manera, sin que haya ninguna dificultad en admitir la evolución. La presente coordinación condiciona nuestro conocimiento, que, salvo el principio de contradicción, es esencialmente correlativo y progresivo, según se perfeccionan los medios cognoscitivos y se desarrolla el hombre. La verdad no es, por tanto, algo puramente estático, sino progresiva y dinámica como la vida del hombre.

$\left.4{ }^{\circ}\right)$ El objeto conocido es un producto de la unión de dos factores, sujeto y objeto, en un único principio operativo (facultad próxima). Esto nos libra de exageraciones subjetivistas y objetivistas: ni objetivismo ni subjetivismo, sino correlacionismo de ambos. La ecuación de la verdad supone que el sujeto crea parcialmente la cosa conocida. Ni las facultades tienen carácter absoluto, ni se contraponen a la realidad, ni la percepción de ésta es absoluta. La verdad y el conocer son una continuación de la correlatividad de lo objetivo y subjetivo, dada por la misma naturaleza vital.

$5 .^{\circ}$ Hay que distinguir dos grandes zonas cognoscitivas:

a) La de las nociones, que garantizan la objetividad del conocer y fundamentan la epistemología; son el punto de partida común a todo conocer humano y en él se unifica toda la filosofía. Es la zona de seguridad y de mayor objetividad, la esfera de daticidad, de lo absoluto dentro de la correlación. Aquí constatamos hechos, hacemos descripciones, pero no definiciones.

La zona nocional tiene también otro aspecto: es el limite de la racionalidad del hombre. No se puede ir más allá de la constatación de esos hechos primarios, de la conciencia de su existencia. Nos señalan el punto final a donde se llega, partiendo de las ideas en sentido regresivo y el único punto de partida en dirección progresiva con carácter absoluto. El ámbito de lo nocional corresponde a la esfera del nous de algunas filosofías. 
b) La zona de los juicios e ideas nos permite hacer definiciones, analizando y sintetizando elementos en correlación. En este ámbito se acentúa la actividad mental y las primeras nociones objetivas se hacen más subjetivas bajo el dinamismo del espíritu humano. Constituye la acotación del terreno en que se mueve el logos propiamente tal, es la zona del conocer intelectual por relaciones.

$\left.6^{\circ} .^{\circ}\right)$ Noción, juicio e idea constituyen una tríada circular del conocimiento humano, que recuerda mucho los movimientos dialécticos de algunos sistemas de filosofía moderna. La noción es el punto de partida del conocer directo, pero, mediante sucesivos análisis y síntesis, se llega a ellas en segunda vuelta de manera refleja. A.R. llama también a esta tríada cognoscitiva: tesis, antitesis y síntesis.

$\left.7^{\circ}\right)$ El individuo existente y concreto tiene en A.R. una prioridad noética y ontológica. El problema es cómo se llega a la universalización y no precisamente cómo se alcanza el individuo, que es punto de partida. El vuelco que se da a la doctrina de algunos escolásticos es total.

8. ${ }^{\circ}$ ) Por la misma razón desaparece esa natura communis, universal e idéntica en los individuos de una misma especie, que hay que sacar por abstracción: a partir del ser individual existente, concreto e histórico, el hombre tiene el poder de concebirlo como reproductible en otros, y al prescindir de esa existencia concreta llega al tipo abstracto, universal, por semejanza, nunca por identidad. Simultáneamente, prescindiendo de la esencia en sus diferentes categorías, se llega a la noción de ente en un segundo momento, que es la misma de que se parte inicialmente.

La doctrina del conocer en A.R. no puede separarse de su ontología, ya que el conocer es una continuación del problema del ser. Por eso, lo anteriormente dicho quedará más completo al considerarlo a la luz de las líneas fundamentales de su ontología» (pp. 617-619).

Según lo que acaba de señalarnos, se centrará ahora en la presentación precisa y preciosa de la antología del pensador compostelano. Como síntesis final escribe:

Brevemente, condensando la exposición anterior, podemos resumir las principales características de esta nueva ontología justamente llamada existencial:

$\left.1^{\circ} .^{\circ}\right)$ Se empieza por el hombre concreto, existente e histórico, que vive en un mundo de correlaciones. De la intrínseca respectividad onto-gnoseológica brota la noción de ente, que con el orden nocional, fundamenta el ser y el conocer, garantizando la objetividad.

El ente nocional es unívoco y de contenido uniforme, aplicado a lo finito e infinito. Por eso no puede ser principio de las categorías o diferencias de seres. El ente categórico, como idea, es análogo tanto respecto a Dios y a las criaturas, como las criaturas entre sí $(9$, n. 518). El universal es un tipo abstracto por semejanza, no por identidad de esencia.

$2^{\circ}$ ) El individuo y supuesto es la primera propiedad del ente concreto, anterior a todas las demás. En los seres inteligentes la persona tiene primacía sobre la naturaleza. El problema de la individuación, que tantos dolores de cabeza ha dado a los tomistas, desaparece como algo ficticio, derivado de comenzar por lo universal, en vez de hacerlo, como A. Ruibal, por el singular y existente, base de todo.

3. ) La categoría de relación pasa ahora a ocupar el puesto fundamental entre los predicamentos y es constitutiva de los seres, en una posición de vanguardia en el pensamiento moderno. La relación y el número, como conceptos aplicables a todos los seres abren grandes horizontes para la filosofía de la ciencia y fundamentación de la logística.

$4^{\circ} .^{\circ}$ El ser concreto es esencialmente dinámico. La causalidad es algo tan íntimo al ser como la vida al ser vivo. Por la causalidad se manifiesta la naturaleza de los seres, que, de ser accidental, sería incognoscible para nosotros. 
5.) No hay distinción real entre la sustancia y los accidentes. Lo mudable es un modo del ser permanente. La sustancia carece en la realidad de permanencia e inmutabilidad como puede apreciarse en cualquier ser vivo, por ejemplo. Posee, en cambio, una inmutabilidad lógica derivada de que continúa la misma relación entre los elementos, aunque éstos se hayan cambiado por completo. Se amplía mucho la noción de sustancia a los seres artificiales, técnicos y artísticos. Lo primero que se conoce es la sustancia y en segundo término aparecen los accidentes como modos de la misma.

$6^{\circ}$ ) Desaparece, como resabio platónico, la esencia absoluta universal, que desciende a los individuos y desaparecen esos posibles como ejemplares y arquetipos eternos. Se empieza por el individuo para llegar a la esencia correlativa, para llegar a lo posible se parte siempre de lo existente. A la ley natural se llega partiendo, igualmente, del actual orden existente, histórico y contingente. El mismo principio de contradicción es algo posterior y consiguiente a un determinado orden actual y sin éste no tendría sentido.

Como observamos en la teoría del conocer sucede también en la del ser: A Ruibal ha invertido los problemas y ha dado un vuelco total a la ontología (ibídem, pp. 637-638).

Estos dos escritos que acabamos de presentar constituyen la visión de conjunto sobre la tarea filosófica de Amor Ruibal, tanto su postura crítica hacia la historia de la filosofía, como su aportación original.

Los otros trabajos que vamos a considerar versan, ya, sobre temas más concretos. Pero en ellos se aprecia un conocimiento muy detallado de toda la extensa obra de Amor Ruibal.

\section{«Interpretación Amorruibalista de la historia de la filosofía y de la teología», Estudios (PP. Mercedarios), XXV (1969), pp. 39-88)}

Este artículo constituye una espléndida presentación de la historiografía ruibaliana, tanto filosófica como teológica. Ciñéndonos tan sólo a la historiografía filosófica, veamos la consideración final que establece nuestro profesor:

La historia de la filosofía puede considerarse como un todo que contiene estos elementos: 1) el conocer de naturaleza y' su zona nocional, que serían el punto de unión de los filósofos de todos los tiempos. No siempre ha sido suficientemente analizada y delimitada esa esfera, pero es algo necesario a la filosofía y se encuentra en todos las elaboraciones. Nadie puede negarla sin afirmarla al mismo tiempo. 2) El conocer de individuo o persona que, partiendo del orden nocional de naturaleza, se hace consciente de las implicaciones de la inserción del hombre en el mundo, originando las nociones de individuo, que deben ser el punto de partida de toda elaboración ulterior. 3) Los sistemas filosóficos, que son los diferentes intentos de cómo, a partir de las nociones de naturaleza y de individuo, se explicitan en un todo armónico que explique el hombre, el mundo y Dios en una visión sintética coherente. La historia, propiamente tal, afecta principalmente al conocer de individuo o persona y a los sistemas por ella construidos; deben señalarse en cada caso los condicionamientos circunstanciales que influyen en las elaboraciones. En el sistema como tal, dentro de la historia de la filosofía, se han de examinar estos cuatro puntos: 1) si delimita y describe de manera adecuada la zona nocional o punto de partida; 2) si la vía progresiva conduce a una visión armónica de todo el orden de la naturaleza, del orden psíquico y del orden teológico natural; 3) si en visión regresiva desde el sistema total se puede retroceder al punto de partida nocional; 4) si la marcha tanto progresiva como regresiva cumple las leyes lógicas de identidad, no-contradicción y coherencia. 
De esta manera veremos si un sistema justifica sus presupuestos, si es lógico en sus consecuencias y si explica los diferentes órdenes de realidad e idealidad sin confundirlos. Un sistema puede ser muy sólido en sus principios y muy ilógico en sus conclusiones y también puede ser de una lógica rigurosa en sus inferencias y muy falso en sus presupuestos ( 9 , págs. $119,104-207)$.

La necesidad de considerar los sistemas en la dimensión histórica, en que se encuentra la persona que origina todos los despliegues dialécticos, obliga a aceptar que no puede nunca existir un sistema definitivo y concluso, ya que existe el progreso y aparecen nuevos aspectos y nuevas dimensiones continuamente (9, págs. 117, 162-163). Es muy parecido a lo que dice Zubiri: «la filosofía no es su historia, pero la historia de la filosofía es filosofía, porque la entrada de la inteligencia en sí misma en la situación concreta y radical en que se encuentra instalada, es el origen y puesta en marcha de la filosofía».

En A. Ruibal esta historicidad se acentúa al ser la persona humana el centro de convergencia de todas las relaciones cognoscitivas y constituirse como yo en punto de referencia de todos los no-yos.

Los PFFD no se limitan a señalar la existencia de multiplicidad de sistemas, sino que continuamente se atiende al crucial problema de las relaciones entre filosofía e historia de la filosofía, señalando con frecuencia lo que puede quedar de permanente y de caduco y explicando la razón de las divergencias y desviaciones. Por eso, la historia debe dar cuenta en concreto del proceso intelectual seguido por cada filósofo y dilucidar el por qué de las numerosas diferencias, debiendo partir todos de la base común y necesaria de naturaleza.

A. Ruibal llevará hasta el máximum sus exigencias y nos asombrará con la enumeración de las soluciones a un problema o con las clasificaciones generales a a partir de una base nocional.

Lo mismo sucede cuando reduce toda la historia de la filosofía a grandes leyes como a las relaciones entre el ente teológico y el ente ontológico, que concreta más en los dos principio generales de la historia de la filosofía: la ley de transcendencia e inmanencia que informan la crítica filosófica de los 10 volúmenes de PFFD (I, págs. 6-7; 5, páginas 255-56).

Por eso, los PFFD son una historia de la «visión de la realidad del Universo y de la realidad de la vida a través de los sistemas filosóficos y teológicos» (CMI, págs. 309-10, indicando la génesis y proceso dialéctico de cada uno de ellos (Vicente Muñoz Delgado, «Interpretación», pp. 65-66).

\section{«Actualidad científica del pensamiento de Amor Ruibal»,}

\section{en Diálogos sobre Amor Ruibal, Madrid, Ed. Revista Estudios, 1970, pp. 75-103}

La aclaración que se realiza en este artículo sobre la concepción filosófica de A. Ruibal y su relación con las ciencias resulta sumamente novedosa en la época en que fue escrita. En estudios actuales sobre A. Ruibal aparecen plenamente confirmadas las apreciaciones de V. Muñoz. Una vez más recojo las palabras conclusivas del escrito, en que se aprecia lo esencial de los desarrollos previos:

Podríamos continuar en esta presentación del ruibalismo, en orden a su capacidad para interpretar la ciencia actual. Los puntos señalados son muy básicos y pueden valer como una muestra de las enormes posibilidades que ofrece A. Ruibal para esclarecer los problemas fundamentales que plantea la ciencia actual. Doy por supuesto que son inservibles cualesquiera de los sistemas de filosofía medieval, por muy meritorios que hayan sido para otra época.

A. Ruibal fue en esto ejemplarísimo. Los problemas han de plantearse desde el mundo y desde el hombre contemporáneo. Nunca desde Aristóteles o desde santo Tomás, ni desde ningún otro. El punto de partida es siempre el hombre situado en orden al mundo. 
Resumiendo, podemos decir que, a nuestro nivel actual, el pensamiento de A. Ruibal ofrece las siguientes posibilidades:

$\left.1 .^{\circ}\right)$ En orden a la verdad revelada y a los posibles conflictos con la ciencia, es muy luminosa la distinción entre conocer directo y conocer reflejo. Como lo revelado es para todos los hombres y para todas las razas y culturas, la fe supone solamente ciertas verdades de orden natural, elementales, como cierta objetividad del conocer, cierta capacidad en el hombre para alcanzar la verdad, la causalidad, la persona y algunas verdades más. Pero, ninguna de ellas se entiende a nivel científico o dentro de un sistema filosófico. Y eso precisamente porque es para todos. Esa distinción es básica en la obra de Ruibal.

2. $\left.{ }^{\circ}\right)$ La ciencia moderna tiene un nuevo modo de hacer experiencias y un instrumental que aumenta la capacidad humana de tal manera que la experiencia científica se contrapone a la vulgar. El filósofo debe empezar por la experiencia científica. La doctrina de la correlatividad onto-gnoseológica permite valorar la diferente posición del aumento de capacidad perceptiva humana y, por consiguiente, el cambio de correlatividad onto-gnoseológica. De ese modo, estamos abiertos a todo posible progreso.

La interpretración ruibalista del hombre en el mundo permite, igualmente, recoger lo mejor de los filósofos vitalistas y existencialistas. La síntesis inicial de sujeto-objeto como totalidad natural es confirmada por la moderna psicología.

Estos dos puntos implican un nuevo punto de partida del filosofar.

$3^{\circ}$ ) La creciente matematización de la ciencia y su progresiva extensión a diferentes ramas del saber encuentran fundamentación en la doctrina ruibalista de la relación, en el número como propiedad transcendental y en el sentido estructural que da a los seres como un sistema de relaciones.

$\left.4^{\circ}\right)$ El método hipotético-deductivo, el predominio de la proposición hipotética, de la proposición de probabilidad, la utilización de estructuras matemáticas para interpretar lo real y la axiomatización no contradicen las bases sistemáticas de Amor Ruibal y pueden engarzarse en sus doctrinas acerca de la relación entre lo real e ideal. Pero es una parte que está menos elaborada en sus textos.

$\left.5^{\circ}\right)$ La doctrina de la sustancia ruibalista con su dinamismo esencial, su doctrina de la causalidad permiten explicar cualquier tipo de evolución. Esa sustancia mudable y dinámica explica igualmente la constitución de la materia, tal como se explica en la actualidad, lo mismo que las diferencias entre los seres materiales.

$\left.6 .^{\circ}\right)$ Como para los griegos el mundo sensible no podía originar ciencia, sino solamente opiniones, la escolástica se sintió muy incómoda para coordinar sus enseñanzas fundamentales con los progresos físico-químicos. Al moverse el mundo grecoescolástico en el nivel de esa esencia inmutable, absoluta y permanente, contrapuesta a los accidentes, no hubo manera de insertar en esa filosofía la ciencia física. Y aún hoy continúan discutiendo sobre la distinción entre física, cosmología y filosofía de la naturaleza. Por el contrario, A. Ruibal armoniza perfectamente sus sistema con la ciencia. Por eso, su filosofía es de máxima actualidad y ofrece grandes posibilidades para corregir algunas crisis originadas por el desfase entre la filosofía escolástica y la ciencia (Vicente Muñoz Delgado, «Actualidad científica», pp. 101103).

\section{«Amor Ruibal y los Sistemas escolásticos», en Ángel Amor Ruibal en la actualidad, Barcelona, CSIC, 1973, pp. 139-186}

Para finalizar esta aproximación a los principales trabajos del profesor salmantino sobre Amor Ruibal, vamos a fijarnos en una publicación que recoge una interesante ponencia que defendió en la Décima Semana Española de Filosofía, que se celebró en Santiago de Compostela, en septiembre de 1969, dedicada a Amor Ruibal al cumplirse el primer centenario de su nacimiento. En la 
ponencia se recoge la crítica ruibaliana al tomismo. Es profunda y demoledora. Una anécdota curiosa al respecto la protagonizan Vicente Muñoz y Guillermo Fraile, ambos, a la sazón, destacados profesores en la Universidad Pontificia de Salamanca. Es bien conocida la postura de G. Fraile hacia el tomismo. Pues bien, V. Muñoz insiste en la demoledora crítica ruibaliana, y esto solivianta al bueno de G. Fraile. Fue una fraternal pugna entre dos colegas y amigos (pero «magis amica veritas»), que recordaba un poco las famosas disputationes del medievo. El cariz de la critica ruibaliana al tomismo lo subraya perfectamente V. Muñoz en el pasaje siguiente:

Como conclusiones de la exposición anterior, me parece que podemos resumir en los siguientes puntos el pensamiento de A. Ruibal acerca de la filosofía de Tomás de Aquino.

$\left.1^{\circ}{ }^{\circ}\right)$ Con los grandes investigadores de la escolástica, posteriores a la obra del filósofo gallego, como Geiger, C. Fabro, Hayen, etc., coincide A. Ruibal en señalar en el tomismo una fuerte carga de elementos neoplatónicos al lado de los aristotélicos. En este sentido, A. Ruibal ha sido un verdadero precursor de otros estudios más sistemáticos realizados con métodos más rigurosos.

2. $\left.{ }^{\circ}\right)$ Respecto al problema de si Tomás de Aquino ha conseguido fundir en síntesis homogénea los elementos platónicos con los aristotélicos, neoplatónicos y estoicos, obteniendo la síntesis de que nos hablan Horvath, Garrigou-Lagrange, Manser, Norberto del Prado, etc., A. Ruibal considera al tomismo como un sincretismo incoherente, sin unidad científica, que se ve obligado a soslayar múltiples inconsecuencias a que llevaría la lógica interna de los varios sistemas que Tomás utiliza según los casos.

No existe manera de evitar los resabios anticristianos que la filosofía griega tiene y, para ello, ha habido que hacer muchas mutilaciones y adaptaciones artificiales, interpretando en aristotélico a los neoplatónicos, pasando continuamente del platonismo al aristotelismo y viceversa, sin tener ni siquiera noción de lo que es un sistema y de la unidad de teoría que exige (VII, 226). Por eso, el tomismo es un sincretismo de elementos heterogéneos, que no puede tener vida al querer fusionar elementos opuestos. Los elementos sistemáticos tomistas desgajados del árbol griego, donde tenían vida, respondían a unos hechos y a unas creencias diferentes de las cristianas, pierden el valor antiguo sin que adquieran ninguno nuevo (VII, 338-339).

3. ${ }^{\circ}$ ) El tomismo no es original ni creación de santo Tomás. El realismo moderado ha sido formulado antes que él; los argumentos de la existencia de Dios se encuentran con anterioridad; de árabes y judíos recibe buena parte de sus elementos «sistemáticos». Otras partes del neotomismo, como el bañecianismo, son posteriores al Angélico, y lo mismo doctrinas como la de la analogía del ente. Puede decirse que Tomás de Aquino es un organizador incomparable, que realiza una gran «síntesis», sin que sea ni un creador ni un pensador de primera categoría (IV, 346). Cuando el tomismo se estudia con profundidad y se llega a la íntima contextura filosófica, entonces aparecen las suturas de los diferentes elementos (VI, 488). «La labor admirable de santo Tomás, que sin ser un genio creador, es un genio organizador [...] no ha sido bastante para la fusión de aquellos encontrados elementos» (VI, 558): Los defectos se refieren a las doctrinas, más que a las personas, que por muy geniales que fuesen no podían superar la incapacidad radical de las teorías griegas para ser aplicadas al cristianismo (VI, 636-637; VII, 67, 67-58, 67, 139; v, 166, 212, etc.).

4..$\left.^{\circ}\right)$ Podemos extender las críticas anteriores a todos los demás escolasticismos, como de hecho hace A. Ruibal, quien se sirve de las mutuas controversias entre los diferentes intentos cristianos de sistematización, para contraponerlos y destruirlos mutuamente, declarando que todos (escotismo, tomismo, suarismo, etcétera) pueden ser simultáneamente falsos (IX, 192-195; 472, nota; VII, 146; 151-158, 163-165, etc.). ¿En qué convienen las aludidas sistematizaciones? Es necesario hacer la distinción con que habíamos comenzado este trabajo: 
1) A nivel sistemático, tomismo y escotismo, cayetanismo y suarismo no convienen en ninguna tesis. De tal manera es verdad que a 24 tesis tomistas se han opuesto otras 24 suaristas. Y el P. Guillermo Fraile, que intenta ser conciliador, pone en su Historia de la Filosofía a dos columnas contrapuestas (p. 1083, t. 2) las principales doctrinas de Escoto y santo Tomás. Luego, a nivel de sistema, no convienen en nada. Ni hay ningún sistema común escolástico de filosofía, sino varios y mutuamente opuestos, de manera que no pueden ser simultáneamente verdaderos, pero sí, al mismo tiempo, falsos. La oposición se refiere precisamente a las tesis más fundamentales, como, por ej., acto y potencia, materia y forma, esencia y existencia, principio de individuación, modo de conocer, etc. En un sistema una tesis fundamental afecta al todo y, por lo tanto, el admitir o no el ejemplarismo, interpretar de modo distinto el acto y la potencia, supone un cambio en el todo del sistema y en sus partes. 2) A nivel presistemático los escolásticos conviene en muchas verdades. Por ej., en la admisión de cierta objetividad del conocer, en distinguir acto y potencia de una manera general, todos admiten la causalidad, una cierta materia y forma de manera indeterminada, un algo que cambia y un algo que permanece, etc. Pero cuando se trata de la visión sistemática de cualquiera de esas verdades, entonces comienzan las discrepancias y contraposiciones.

Podemos, pues, concluir que a nivel sistemático no ha habido una filosofía perenne ni indiscutida en los siglos escolásticos y neoescolásticos. A nivel presistemático todos estamos de acuerdo en ciertas verdades que se preexigen para la inteligencia y sentido del mensaje revelado. Pero esas verdades presistemáticas no son propiamente filosóficas, sino pertenecientes al conocer primario o de naturaleza, común a todos los hombres, derivado de nuestra inserción en el mundo y que sería el punto de partida de todo recto filosofar (VIII, 227-234).

La delimitación de ese conocer primario, común a todos los que pertenecen a la categoría cognoscitiva humana, sería la base para un ecumenismo filosófico y el punto de unión de todos. Bien delimitado ese conocer nocional y primario es suficiente para la inteligencia de lo revelado. Por ahí es por donde se puede llegar a la síntesis común escolástica. Pero no parece que exista en todo el escolasticismo cristiano ninguna síntesis común a nivel de sistema, como quería M. De Wulf, ni un patrimonio común a lo Baeumker, ni ninguna filosofía perennis. Puede admitirse una especie de espíritu común, a lo Gilson, o una filosofía en sentido muy lato, como dice Van Steenberghen. Pero filosofía sistemática, en sentido riguroso, no existe ninguna común en los escolásticos.

Tenemos, pues, muchos filósofos cristianos, pero ningún sistema de filosofía escolástica que haya merecido la aprobación de todos.

5.) Para A. Ruibal todos los escolasticismos adolecen de los defectos señalados en el tomismo y a todos considera igualmente inútiles, con resabios anticristianos, sincretismos artificiales y sin vida. Como consecuencia, se impone una revisión profunda de la filosofía (VI, 637). A. Ruibal es, pues, un antiescolástico y pretende anular todo el pensamiento sistemático derivado de las escuelas griegas, como inservible para las elaboraciones cristianas (V, 66,212 ; VI, 271-274, etc.). La filosofía griega es inservible de iure y el estudio de la escolástica confirma que también lo es de facto en las múltiples adaptaciones intentadas.

$\left.6^{\circ}{ }^{\circ}\right)$ Pienso que para entender a Amor Ruibal hay que situarse en esa plataforma antiescolástica. Desde ahí ha de investigarse dónde de hecho se encuentra su posición personal. Al menos de intención, fue antiescolástico, como demuestran todos los volúmenes de PFFD. Toda su crítica encuentra sentido para abrirse paso y despejar el solar en que habría de construir su propia sistemática. No se trata, por tanto, de ningún escolástico, sino de un antiescolástico (Vicente Muñoz Delgado, «Amor Ruibal», pp. 182-185).

Como punto final, unas palabras de recuerdo y gratitud para el Maestro y Amigo Vicente Muñoz. Su ironía y humor lo recordaremos siempre los que tuvimos el privilegio de ser sus discí- 
pulos y amigos. El saber que profusamente adquirió y generosamente transmitió de forma oral, también está consignado en escritos de enorme valor. Confiamos en que haya recibido el definitivo ciento por uno en su Nueva Vida.

\author{
César Raña Dafonte \\ Departamento de Filosofía y Antropología \\ Social \\ Facultad de Filosofía y CC Educación \\ E-15706 SANTIAGO DE COMPOSTELA
}

